CAHIER DE RECHERCHE \#1610E

Département de science économique

Faculté des sciences sociales

Université d'Ottawa
WORKING PAPER \#1610E

Department of Economics

Faculty of Social Sciences

University of Ottawa

\title{
Technological Progress and Sectoral Shares
}

\author{
Gamal Atallah $^{*}$ and Aggey Semenov ${ }^{\dagger}$
}

August 2016

\footnotetext{
* Department of Economics, University of Ottawa, 120 University Private, Ottawa, Ontario, Canada, K1N 6N5; email: Gamal.Atallah@uottawa.ca.

${ }^{\dagger}$ Department of Economics, University of Ottawa, 120 University Private, Ottawa, Ontario, Canada, K1N 6N5; email: Aggey.Semenov@uottawa.ca.
} 


\begin{abstract}
This paper studies the effect of differences in the rate of technological progress between sectors on the relative sizes of those sectors in terms of revenues. There are two sectors: a stagnant sector, where productivity does not change over time, and a progressive sector, where costs decrease over time due to exogenous technological progress. We consider a conjectural variation approach to competition in the progressive sector which encompasses perfect competition, Cournot oligopoly and monopoly. The main result of the paper is that the share of the stagnant sector increases over time when demand in the progressive sector is inelastic. Under perfect competition, when initial production costs in the progressive sector are sufficiently low (so that demand is inelastic), the share of the stagnant sector rises over time. Whereas, when initial production costs are sufficiently high (so that demand is elastic), the relative size of the stagnant sector is U-shaped with respect to time. Under monopoly, the share of the stagnant sector always decreases over time. However, the decline in that share is much more rapid the higher are initial costs in the progressive sector. The interaction of market structure and price elasticity (or initial costs) determines how the relative sizes of sectors differing in productivity growth evolve over time. The relationship with the cost disease literature is discussed.
\end{abstract}

Key words: Cost decrease, productivity growth, sectoral shares, cost disease.

JEL Classification: D24, D41, D42, L11, O33. 


\section{Introduction}

Productivity growth varies greatly between sectors, even within the same country. For example, in Canada and the U.S. labour-productivity growth has been significantly slower in the business services sector than in the manufacturing sector over the period 1962-1988 (Crawford, 2002). In the U.S., output per hour and multifactor productivity have been growing much more rapidly (about three times faster) in high-tech industries than in the overall manufacturing sector (Kask and Sieber, 2002). The health-care sector is known to have low productivity growth; for example, studying productivity growth in health-care delivery in 19 OECD countries for the period 19741989, Fillic et al. (1997) find very limited productivity growth. Labour productivity growth in the education sector in the U.S. for the period 1990-2002 was -0.30 per annum (O'Mahony and Stevens, 2009).

Such differences in productivity growth, when they persist for extended periods of time, can have important implications for the relative size of sectors. Does a sector with higher productivity necessarily grow faster over time relative a sector with slower growth? This is the question to which we aim to provide a theoretical answer in this paper.

We analyze an economy consisting of two sectors: a stagnant sector, where productivity does not change over time, and a progressive sector, where costs decrease over time due to exogenous technological progress. We consider a conjectural variation approach to competition in the progressive sector which encompasses perfect competition, Cournot oligopoly and monopoly. The main result of the paper is that the share of the stagnant sector increases over time when demand in the progressive sector is inelastic. As applications we consider two market structures: perfect competition and monopoly. We compare the relative sizes of sectors by comparing the revenues they generate.

We find that under perfect competition, when initial production costs in the progressive sector are low, the share of the stagnant sector rises over time. Whereas, when initial production costs are sufficiently high, the relative size of the stagnant sector is U-shaped with respect to time. This is because when initial costs are low, we are on the inelastic portion of the demand curve, thus technological progress, which reduces costs and prices, decreases revenues in the progressive sector, leading to an increase in the share of the stagnant sector. Things get more complicated when initial costs in the progressive sector are high, so that we are on the elastic portion of the demand curve. 
In that case, initial cost and price declines increase revenues in the progressive sector, reducing the share of the stagnant sector. However, the continuing decrease in costs will eventually take prices to the inelastic part of the demand curve, leading to an increase in the share of the stagnant sector over time after a certain number of periods.

Under monopoly, because demand is always elastic in equilibrium, the share of the stagnant sector always decreases over time, irrespective of whether initial costs in the progressive sector are low or high. However, the decline in that share is much more rapid the higher are initial costs in the progressive sector.

Thus, the interaction of market structure and price elasticity (or initial costs) determines how the relative monetary revenues of sectors differing in productivity growth evolve over time.

This issue is related to the literature on the cost disease (starting with Baumol and Bown, 1966), which argues that (stagnant) sectors with a heavy labor component which cannot be mechanized face low productivity growth, rising salaries relative to other (progressive) sectors (to attract workers to stagnant sectors), and claim an increasing share of government and consumer expenditures over time. The performing arts, education, health care, and other personal services are typical examples. The policy implications are that governments have to accept the inevitable increase of these costs over time, and that society can afford to do so (Baumol, 2012).

The cost disease view has both its supporters (for example, Trombella, 2010) and its detractors (for example, Cowen, 1996). By showing that the share of the stagnant sector may increase or decrease over time (or both) depending on market structure and initial price elasticity (or initial costs) in the progressive sector, this paper contributes to this literature, suggesting that the cost disease holds in certain circumstances, but not in others. The paper is concerned only about the relative sizes of the stagnant and progressive sectors in terms of revenues; it says nothing about wages.

The results also have implications for measurement of aggregate productivity growth. When the stagnant sector occupies a large share of the economy, aggregate productivity growth will be lower. On the other hand, when the share of the stagnant sector in economic activity is small, aggregate productivity will be growing faster over time. Thus, the observed slowdown in productivity growth in several developed economies over the last few decades may be due, in part, to the large share that the education, health, etc. sectors occupy in those economies. 
The paper is organized as follows. In section 2, we present and solve the model and characterize the change in shares over time as a function of the price elasticity of demand and of conjectural variations. In section 3 we illustrate the results under perfect competition and monopoly with linear demand and costs. Section 4 concludes.

\section{The model}

There are two sectors producing homogenous goods $X$ and $Y$ respectively. Think of $X$ and $Y$ as the service and the high-tech sectors of the economy respectively. It is clear that there is not much competition for resources between these sectors. Therefore, general equilibrium effects are not relevant for our model. These effects, for example the effect on wages of workers or the effect on prices of raw materials, can be relevant for sectors which operate in the same industry. Workers in hotel services or in restaurant services can easily switch jobs with little or no training. However, high-tech industries have very inelastic job supply and require extensive training. Markets operate in periods $t=1,2, \ldots, T$, where $T$ can be finite or infinite. Demands for both goods are time invariant. ${ }^{1}$ Good $X$ is stagnant, in the sense that its cost does not change over time. Thus, the revenue $R_{X}$ of sector $X$ is constant over time.

Good $Y$ is produced by $N$ identical firms with cost function $c\left(y_{i}, t\right)$, where $y_{i}$ is the output of firm $i$ at date $t$. Good $Y$ is progressive, in the sense that its marginal cost decreases over time through exogenous technological progress. ${ }^{2}$ For each firm $i=1,2, \ldots, N$ in sector $Y$ we assume that

$$
\partial\left(\frac{\partial c\left(y_{i}, t\right)}{\partial y}\right) / \partial t<0
$$

Slightly abusing notations we denote by $X$ and $Y$ the name of the good/sector, and also the total quantity produced in the progressive sector: $Y=\sum_{i=1}^{N} y_{i}$.

Demand in sector $Y$ is given by $Y=Y(p)$ with the inverse demand function $p=p(Y)$. Firms in sector $Y$ maximize profit at each $t$. Note that the two goods are unrelated from a consumption point of view.

\footnotetext{
${ }^{1}$ We discuss the possibility of changing demands in conclusion.

${ }^{2}$ This can represent a sector where labor-saving technologies reduce costs over time.
} 
Assumption 1 Demand in sector $Y$ and the cost function $c(y, t)$ are twice differentiable; $Y(p)$ is a decreasing function; $c(y, t)$ is convex in $y$; optimal price and quantity are interior for each date $t$.

This assumption is standard and allows us to use the first-order approach to characterize the optimal solution for sectors. We are interested in how the relative and absolute sizes of the two sectors evolve as technological progress reduces costs in the progressive sector $Y$. As sector $X$ remains unchanged over time, everything will be determined by movements in price and output in sector $Y$.

We assume that each firm $i$ conjectures the reaction of the remaining firms $j \neq i$ on changes in its output:

$$
\beta=\frac{d\left(\sum_{j \neq i} y_{j}\right)}{d y_{i}} \in[-1, N-1] .
$$

This parameter - conjectural variation - is assumed to be same for all firms (see for example Perry, 1982). We consider a static conjectural variations approach which is the reduced form of the equilibrium of a dynamic game. Cabral (1995) shows that this solution concept holds for a quantity-setting repeated game with minimax punishments during $T$ periods. ${ }^{3}$ We have:

$$
\frac{d \pi_{i}}{d y_{i}}=p\left(y_{i}+\sum_{j \neq i} y_{j}\right)+(1+\beta) p^{\prime}\left(y_{i}+\sum_{j \neq i} y_{j}\right) y_{i}-\frac{\partial c\left(y_{i}, t\right)}{\partial y} \text { at each } t
$$

Because firms are identical we focus on a symmetric equilibrium. The equilibrium quantity in sector $Y$ is characterized by:

$$
p(Y)+(1+\beta) \frac{d p(Y)}{d Y} \frac{Y}{N}-\frac{\partial c\left(\frac{Y}{N}, t\right)}{\partial y}=0
$$

This condition defines the total quantity and price as functions of $\beta$ and $t: Y(\beta, t)$ and $p(\beta, t)=$ $p(Y(\beta, t))$. The total revenue in sector $Y$ is $R_{Y}(\beta, t)=p(Y(\beta, t)) Y(\beta, t)=p(\beta, t) Y(p(\beta, t))$.

The equilibrium condition (2) includes:

\footnotetext{
${ }^{3}$ See also Kalai and Stanford (1982) who study the game theoretic foundations of the conjectural variations concept. They show that in the infinitely repeated duopoly game the non-zero conjectural equilibria exist and their properties agree with economic intuition.
} 
- Perfect competition. In this case each firm has the "Bertrand Conjecture": $\beta=-1$. Each firm $i$ conjectures that other firms will reduce their outputs to exactly offset firm $i^{\prime} s$ increase. Thus total output and price remain unchanged. We have in this case $p(Y)=c^{\prime}\left(\frac{Y}{N}\right)$.

- Cournot oligopoly. In this case each firm has the "Nash Conjecture": $\beta=0$. Each firm $i$ treats the output of the other firms as given. We have $p(Y)+p^{\prime}(Y) \frac{Y}{N}=c^{\prime}\left(\frac{Y}{N}\right)$.

- Monopoly. In this case each firm behaves as the joint profit maximizer: $\beta=N-1$. We have $p(Y)+p^{\prime}(Y) Y=c^{\prime}\left(\frac{Y}{N}\right)$.

In general, the higher is $\beta$, the less competitive is sector $Y$.

The share $S_{X}$ of sector $X$ is (we also denote by $S_{Y}$ the share of sector $Y: S_{Y}=1-S_{X}$ )

$$
S_{X}=\frac{R_{X}}{R_{X}+R_{Y}}=\frac{1}{1+\frac{R_{Y}}{R_{X}}} .
$$

Note that since $R_{X}$ is $t$ and $\beta$ invariant, only changes in $R_{Y}$ matter. We have for $s \in\{\beta, t\}$

$$
\begin{gathered}
\frac{\partial R_{Y}(\beta, t)}{\partial s}=\frac{\partial p(\beta, t)}{\partial s} Y(p((\beta, t)))+p(\beta, t) \frac{d Y(p(\beta, t))}{d p} \frac{\partial p(\beta, t)}{\partial s}= \\
\frac{\partial p(\beta, t)}{\partial s} Y(p((\beta, t)))\left(1+\frac{d Y(p((\beta, t)))}{d p} \frac{p(t)}{Y(p((\beta, t)))}\right)=\frac{\partial p(\beta, t)}{\partial s} Y(p((\beta, t)))(1+\varepsilon(\beta, t)),
\end{gathered}
$$

where $\varepsilon(\beta, t)=\frac{d Y(p((\beta, t)))}{d p} \frac{p(\beta, t)}{Y(p((\beta, t)))}$ is the price elasticity of demand.

Consider the evolution of price elasticity depending on time or the level of competitiveness:

$$
\frac{\partial \varepsilon(\beta, t)}{\partial s}=\frac{\frac{\partial p(\beta, t)}{\partial s}}{Y(p(\beta, t))}\left(\frac{d^{2} Y(p(\beta, t))}{d p^{2}} p(\beta, t) Y(p(\beta, t))+\frac{d Y(p(\beta, t))}{d p} Y(p(\beta, t))-\left(\frac{d Y(p(\beta, t))}{d p}\right)^{2} p(\beta, t)\right) .
$$

Note that the expression in brackets is negative if $\frac{d^{2} Y(p)}{d p^{2}} \leq 0$. We assume

Assumption 2 Assume that $\frac{d^{2} Y(p)}{d p^{2}} p Y(p)+\frac{d Y(p)}{d p} Y(p)-\left(\frac{d Y(p)}{d p}\right)^{2} p<0$.

This assumption is similar to the concavity of the profit function used in Aguirre and Vickers (2010). A sufficient condition is that the demand $Y(p)$ is a concave function. ${ }^{4}$ However, this

\footnotetext{
${ }^{4}$ Concave demand functions were used in previous studies (see for example Gabszwicz and Thisse, 1986, Aguirre et al. 2010).
} 
condition is stronger than we need. For example the exponential demand (see Aguirre and Vickers, 2010, p. 1606) $Y(p)=B e^{-p / b}$ (with $B$ and $b$ positive) is not concave in $p$, but Assumption 2 is satisfied. Indeed we have $\frac{d^{2} Y(p)}{d p^{2}} p Y(p)+\frac{d Y(p)}{d p} Y(p)-\left(\frac{d Y(p)}{d p}\right)^{2} p=-\frac{B^{2}}{b} e^{-2 p / b}<0$.

Under this assumption we have:

$$
\operatorname{sign}\left(\frac{\partial \varepsilon(\beta, t)}{\partial s}\right)=-\operatorname{sign}\left(\frac{\partial p(\beta, t)}{\partial s}\right)
$$

The next subsections will determine the right hand side and therefore the evolution of elasticity depending on time and competitiveness.

\section{Evolution over time}

Differentiating (2) with respect to $t$ we obtain

$$
\begin{gathered}
\frac{\partial Y(\beta, t)}{\partial t}\left(\frac{d p(Y(\beta, t))}{d Y}\left(1+\frac{1+\beta}{N}\right)+(1+\beta) \frac{d^{2} p(Y(\beta, t))}{d Y^{2}} \frac{Y(\beta, t)}{N}-\frac{1}{N} \frac{\partial^{2} c(Y(\beta, t) / N, t)}{\partial y^{2}}\right)= \\
=\frac{\partial^{2} c(Y(\beta, t) / N, t)}{\partial y \partial t}<0 .
\end{gathered}
$$

By Assumptions 1 and 2 we have $\frac{\partial Y(\beta, t)}{\partial t}>0$ and, therefore,

$$
\frac{\partial p(\beta, t)}{\partial t}<0
$$

Thus, from (3) the dynamics of the revenue share of the progressive sector are determined by the evolution of the elasticity of demand over time. We have the following:

Proposition 1 a) If $\varepsilon(\beta, 1)>-1$ then technological progress in sector $Y$ increases the share of the stagnant sector $X$ for all t;

b) If $\varepsilon(\beta, 1)<-1$ and $\varepsilon(\beta, T)>-1$ then there exists $\widehat{t}$ such that the share of the stagnant sector decreases for $t \leq \widehat{t}$ and then increases for all $t>\widehat{t}$;

c) If $\varepsilon(\beta, T) \leq-1$ then technological progress in sector $Y$ decreases the share of the stagnant sector $X$ for all $t$. 
Proof. Note that the term $1+\varepsilon(\beta, t)$ in $(3)$ is an increasing function in $t$.

Cost decrease in the progressive sector reduces price in that sector. That price decrease will increase revenues in the progressive sector, and thus its share in total revenues from the two sectors, if demand is elastic. Otherwise, if demand in the progressive sector is inelastic, the cost and ensuing price decrease will decrease revenues in that sector, decreasing its share and increasing the share of the stagnant sector over time.

Our assumptions allow us to obtain a monotonic increase in elasticity over time. Still we have sufficiently rich possibilities of evolution of shares of sectors given competitiveness in sector $Y$ is fixed.

\section{The effect of competition}

Consider now how competition in the progressive sector affects revenues. Differentiating (2) with respect to $\beta$ we obtain

$$
\begin{gathered}
\frac{\partial Y(\beta, t)}{\partial \beta}\left(\frac{d p(Y(\beta, t))}{d Y}\left(1+\frac{1+\beta}{N}\right)+(1+\beta) \frac{d^{2} p(Y(\beta, t))}{d Y^{2}} \frac{Y(\beta, t)}{N}-\frac{1}{N} \frac{\partial^{2} c(Y(\beta, t) / N, t)}{\partial y^{2}}\right)= \\
=-\frac{d p(Y(\beta, t))}{d Y} \frac{Y(\beta, t)}{N}>0 .
\end{gathered}
$$

We have $\frac{\partial Y(\beta, t)}{\partial \beta}<0$ and, therefore,

$$
\frac{\partial p(\beta, t)}{\partial \beta}>0
$$

Note that the effect of the conjectural variation on price is negative. The lower is competition in the progressive sector ( $\beta$ is higher) the higher is the price and the lower is output in that sector. This is consistent with monopolization of the progressive sector; the monopolist has the highest price and the lowest output. For monopoly we have $\varepsilon<-1$ and, therefore, by (3) and (5) $\frac{\partial R_{Y}(\beta, t)}{\partial t}>0$. Thus the share of the progressive sector is increasing over time uniformly. Moreover, by (4) we have $\frac{\partial \varepsilon(\beta, t)}{\partial \beta}<0$. We obtain

Proposition 2 a) Under monopoly the share of the stagnant sector is decreasing over time;

b) There exists $\widehat{\beta} \in[-1, N-1)$ such that for all $\beta \geq \widehat{\beta}$ technological progress in sector $Y$ decreases the share of the stagnant sector $X$ for all $t$. 
For a sufficiently monopolized sector the price and output lie on the elastic part of the demand curve. Thus, the revenue share of the progressive sector is increasing over time.

\section{Applications}

Consider the linear inverse demands $p_{X}=A_{X}-b_{X} X$ and $p_{Y}=A_{Y}-b_{Y} Y$ and cost functions $c(X)=\alpha_{X} X, c(Y, t)=(1-k)^{t-1} \alpha_{Y} Y$, where $\alpha_{Y} \in\left(0, A_{Y}\right)$ is the initial marginal cost in the progressive sector and $k \in(0,1)$ is the cost - reducing factor. Then we have $\partial\left(\frac{\partial c(Y, t)}{\partial Y}\right) / \partial t=$ $(1-k)^{t-1} \alpha_{Y} \ln k<0$.

\section{Perfect competition}

Under perfect competition: $\beta=-1$. Equilibrium price and quantity are $p(t)=\frac{\partial c(Y, t)}{\partial Y}=(1-k)^{t-1} \alpha_{Y}$ and $Y(p(t))=\frac{A_{Y}-(1-k)^{t-1} \alpha_{Y}}{b_{Y}}$.

The elasticity of demand at date $t$ is

$$
\varepsilon(t)=\frac{d Y(p(t))}{d p} \frac{p(t)}{Y(p(t))}=\left(-\frac{1}{b_{Y}}\right) \frac{(1-k)^{t-1} \alpha_{2}}{\left(\frac{A_{Y}-(1-k)^{t-1} \alpha_{Y}}{b_{Y}}\right)}=-\frac{(1-k)^{t-1} \alpha_{Y}}{A_{Y}-(1-k)^{t-1} \alpha_{Y}} .
$$

We have $\varepsilon(1)>-1$ if $\alpha_{Y}<\frac{A_{Y}}{2}$.

Corollary 1 Under perfect competition with linear demands and costs:

a) If $\alpha_{Y}<\widehat{p}=\frac{A_{Y}}{2}$, technological progress in the progressive sector uniformly increases the share of the stagnant sector over time.

b) If $\alpha_{Y} \geq \widehat{p}=\frac{A_{Y}}{2}$, technological progress in the progressive sector first decreases, then increases the share of the stagnant sector over time. The increase in this share starts to occur in period $t$ such that, $c(Y, t-1) \geq \frac{A_{Y}}{2}>c(Y, t)$.

As costs decrease over time in sector $Y$, prices in that sector will decrease. And we know that a price decrease increases revenue if and only if demand is elastic. The point separating elastic from inelastic regions on the demand curve is the middle of the curve, given by $\widehat{p}=\frac{A_{2}}{2}$. Starting at a 
period where $p(t) \leq \widehat{p}$, technological progress will reduce next period's cost and price, decreasing revenue relative to period $t$. Similarly, starting at a period where $p(t)>\widehat{p}$, technological progress will reduce next period's cost and price, increasing revenue relative to period $t$.

Consider the case where initially costs (in the progressive sector) are low, so that we are on the inelastic portion of the demand curve of sector Y. As costs and prices continue to decrease, we remain in the inelastic region, and $R_{Y}$ and $S_{Y}$ must decrease over time. This means that the relative importance of the stagnant sector, $S_{X}$, is increasing over time.

Figures 1 and 2 illustrate this case. For all figures we use the following numerical parametrization: $A_{X}=A_{Y}=1000, b_{X}=b_{Y}=1, k=0.05$. The results do not depend on the specific numbers chosen, or the symmetry between the two sectors (although the symmetry gives each sector a share of $50 \%$ in period 1).

Figure 1. Shares under perfect competition (low cost)

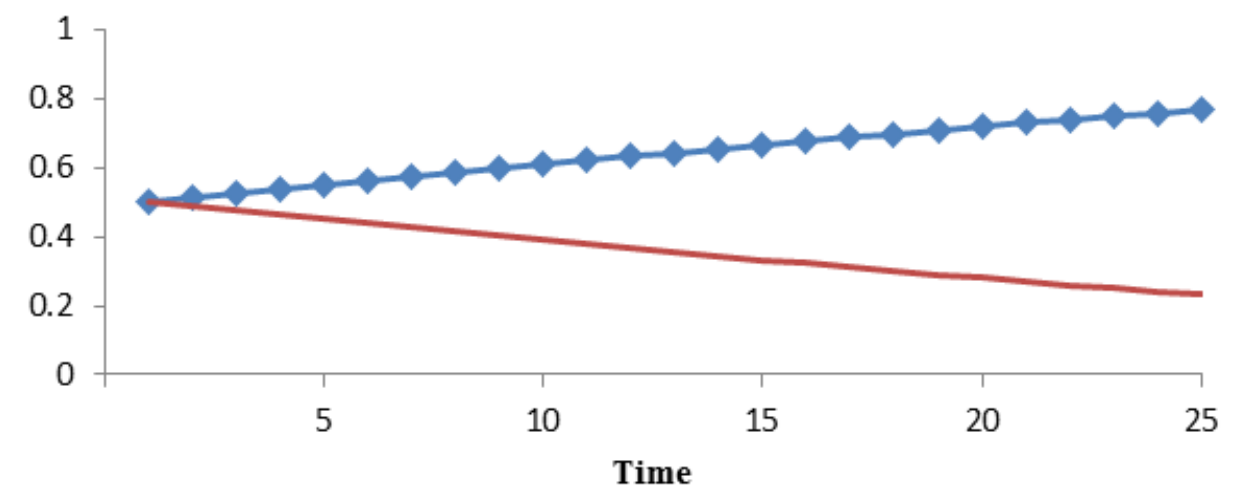

$\multimap$ Stagnant sector $\quad$ Progressive sector 
Figure 2. Revenues under perfect competition

(low cost)

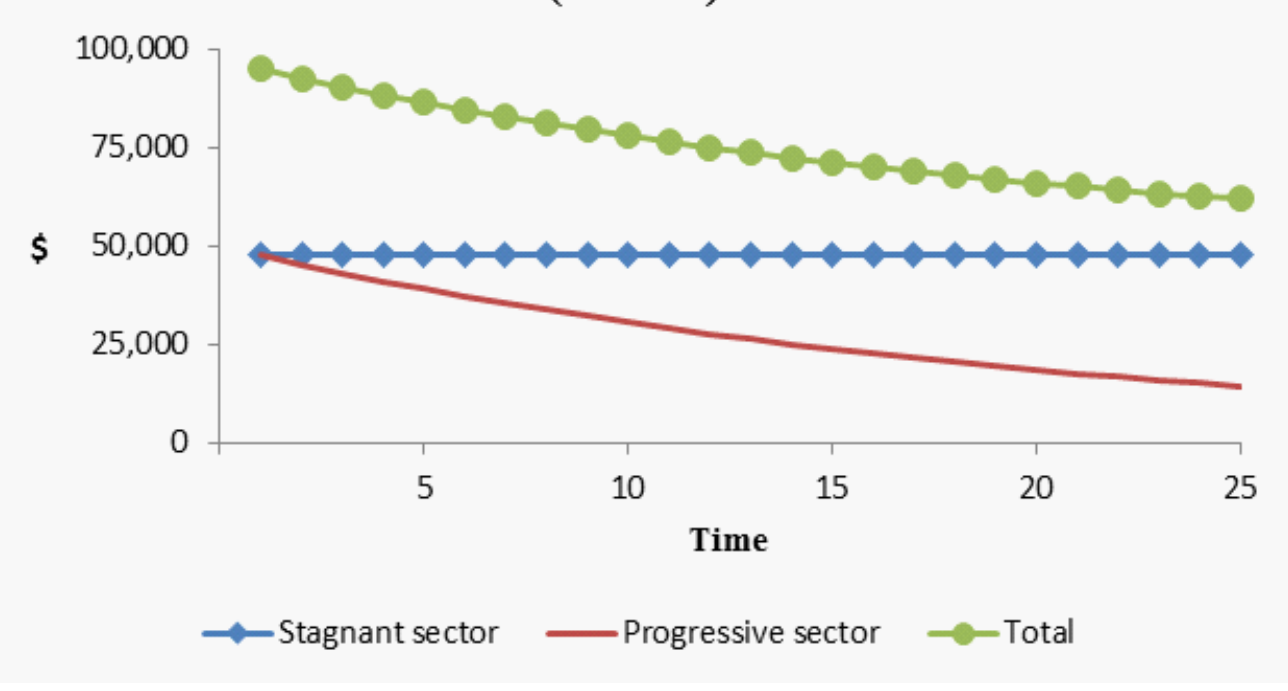

On figures 1 and 2 we chose a "low" value of $\alpha_{X}=\alpha_{Y}=50$, resulting in a price which is well below the middle of the demand curve given by $\widehat{p}=1000 / 2=500$. Figure 1 shows that the share of the stagnant sector rises, and the share of the progressive sector decreases over time. Figure 2 shows revenues in dollars. As this figure shows, it is the decline in the revenues in sector $Y$ which reduces $S_{Y}$ over time.

The results are different, however, if costs are initially high. Assume $\alpha_{X}=\alpha_{Y}=900$, so that first period prices in sector $Y$ are on the elastic portion of the demand curve. In that case, initial cost and price decreases must increase revenues in sector $Y$, until we reach $\widehat{p}$. Once we reach this critical value, we are on the inelastic portion of the demand curve, and further cost and price decreases must decrease $R_{Y}$. Figures 3 and 4 illustrate this case. On figure 3, initially, the share of the stagnant sector is decreasing over time, because of the rise in revenues in the progressive sector. However, as soon as $p_{Y}$ reaches $\widehat{p}, R_{Y}$ starts to decline, and $S_{X}$ starts to increase. In the example taken here, if each period represents one year, it takes 12 years for the stagnant sector before starting to rise in relative terms, and over four decades for $S_{X}$ to overtake $S_{Y}$. 
Figure 3. Shares under perfect competition

(high cost)

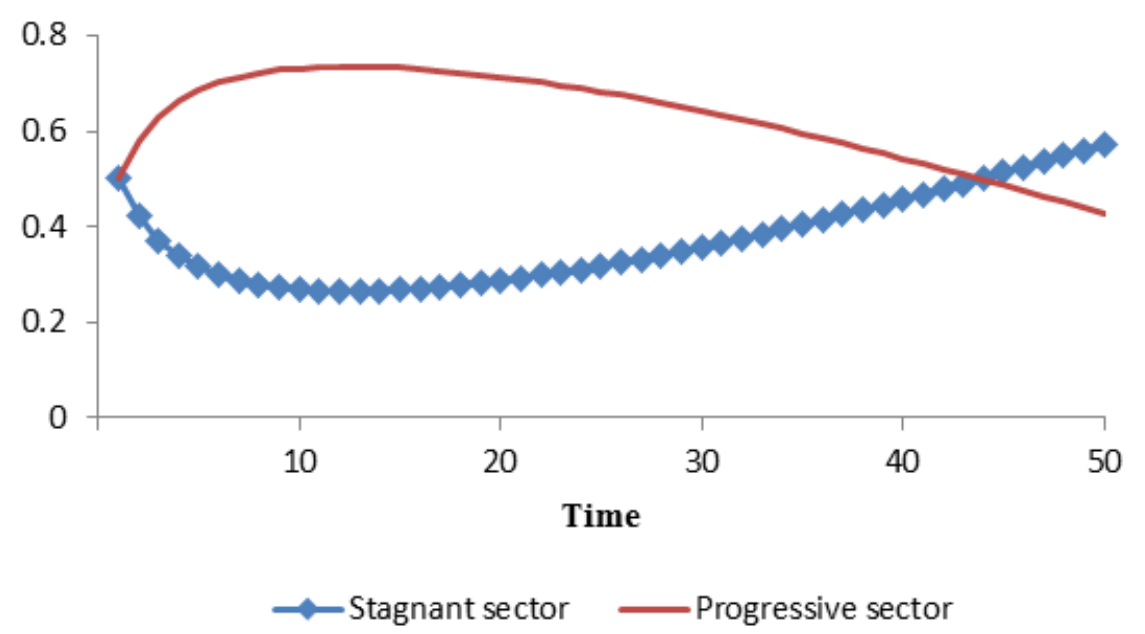

Figure 4. Revenues under perfect competition (high cost)

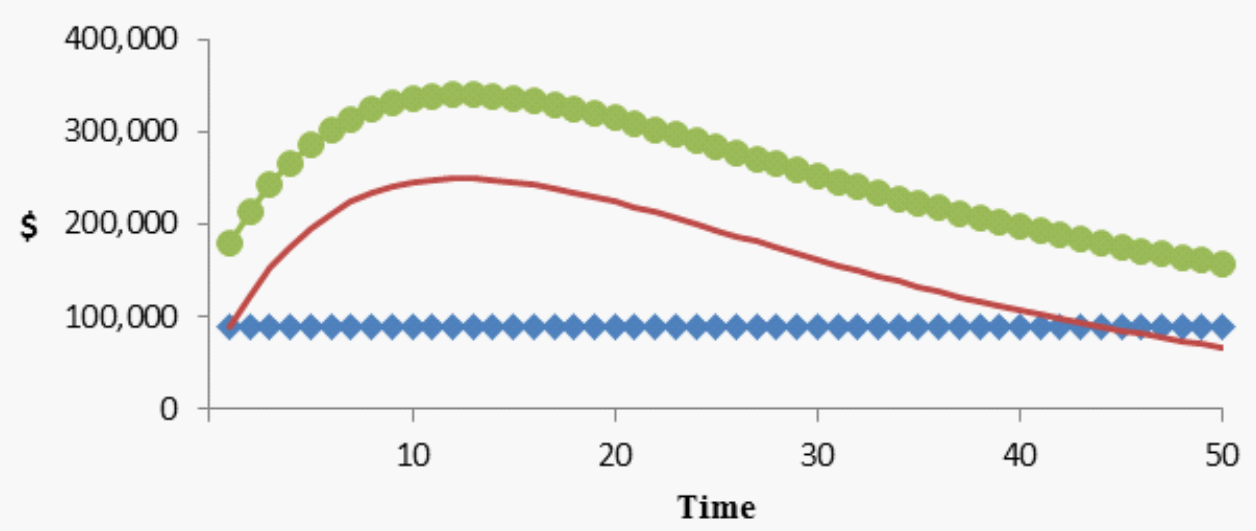

$\multimap$ Stagnant sector $\_$Progressive sector $\quad$-Total

\section{Monopoly}

Consider now the case where each sector is operated by a (different, although this doesn't matter) monopolist. Under monopoly we have the following result.

Corollary 2 When the progressive sector is monopolized, technological progress in that sector reduces the share of the stagnant sector, the more so when initial costs in the progressive sector are higher. 
Because in the monopoly equilibrium demand is elastic, the price decrease which follows from technical progress always increases $R_{Y}$. It follows that $S_{X}$ must decrease over time.

Figure 5 illustrates $S_{X}$ and $S_{Y}$ in the case where initial costs are low $\left(\alpha_{X}=\alpha_{Y}=50\right)$. In that case $S_{X}$ decreases over time, but the decline is rather negligible, so that the shares are still extremely close to $50 \%$ even after 25 periods. The low initial cost in the progressive sector implies that the change in dollars in unit costs in that sector is negligible; given that the monopolist passes only half the cost change to consumers, the overall effect on $R_{Y}$ is very small. Figure 6 illustrates the negligible increase in $R_{Y}$ over time.

Figure 5. Shares under monopoly

(low cost)

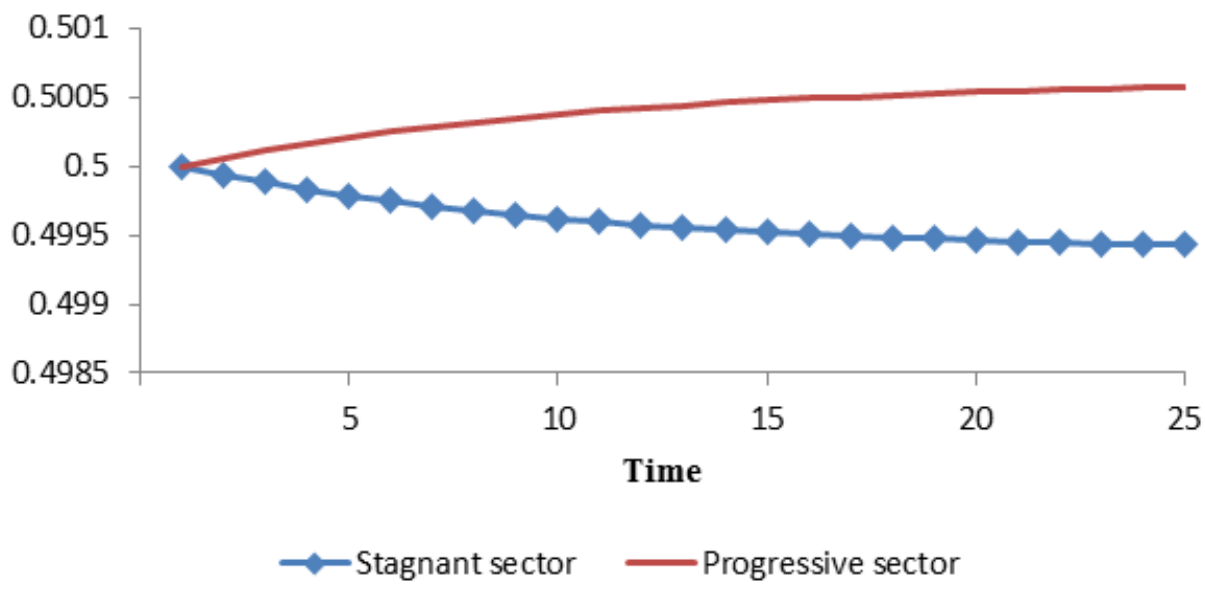

Figure 6. Revenues under monopoly (low cost)

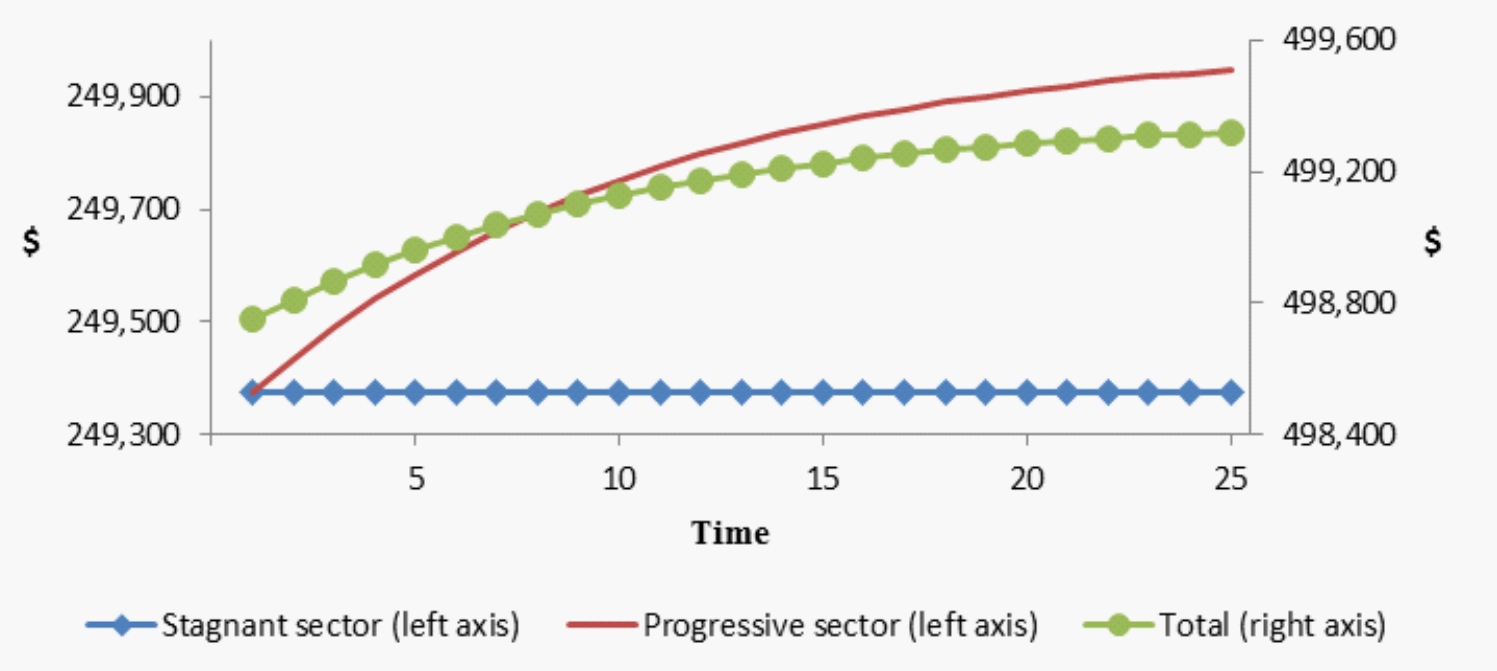


Figure 7 illustrates $S_{X}$ and $S_{Y}$ under monopoly when initial costs are high: $\alpha_{X}=\alpha_{Y}=900$. In that case the share of the stagnant sector decreases rapidly, and hovers below $17 \%$ after only 25 periods. Figure 8 shows the substantial increase in $R_{Y}$ over time.

\section{Figure 7. Shares under monopoly \\ (high cost)}

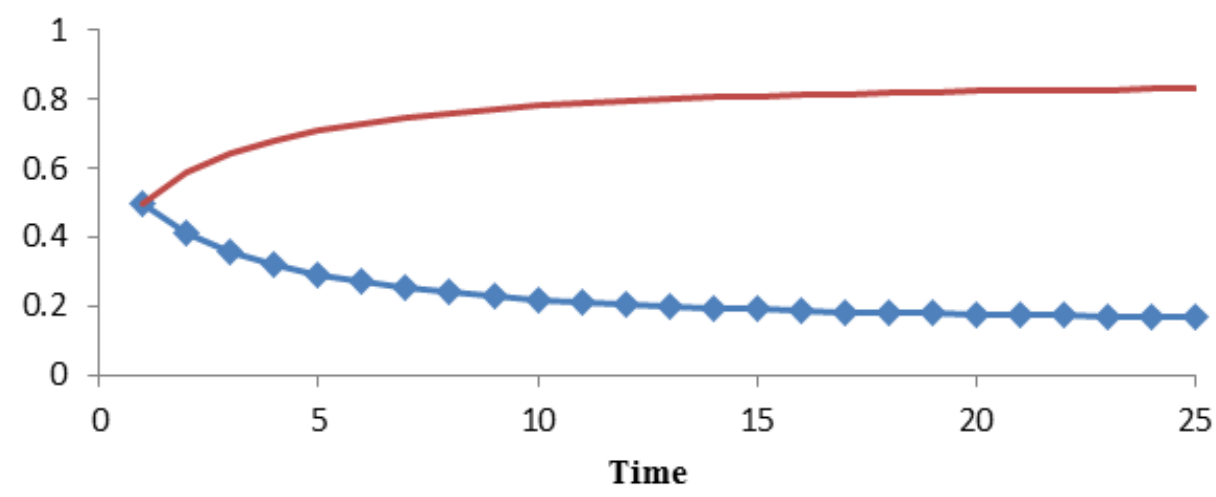

- Stagnant sector $\quad$ Progressive sector

Figure 8. Revenues under monopoly

(high cost)

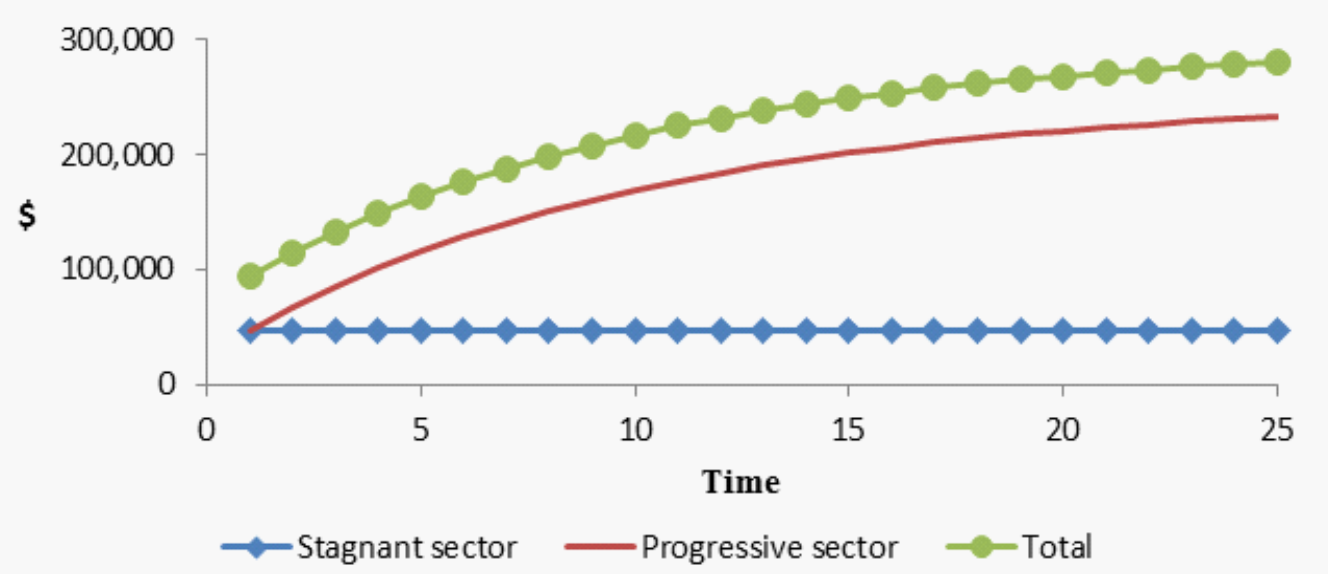

Note that what matters for this result is that the progressive sector is monopolized: the level of competition in the stagnant sector does not play any role. 


\section{Conclusion}

We have shown how the relative sizes of a stagnant sector -where productivity remains unchanged over time - and a progressive sector - where costs decrease over time- depend on market structure and initial costs (and thus price elasticity).

Of course, demand conditions may change over time, and demand increase in the stagnant sector may be more or less important than demand increase in the progressive sector. Demand increase in the stagnant sector would simply increase its share. Demand increase in the progressive sector has the direct effect of increasing its share, but has the indirect effect of increasing the likelihood (or bringing forward the date such) that price in the progressive sector is on the inelastic portion of the demand curve, inducing a negative effect of technological progress on the share of the progressive sector. The basic result remains: the position of the current price in the progressive sector relative to the (possibly shifting over time) elasticity of demand in the progressive sector will play a critical role in determining how the relative shares of the two sectors evolve.

In this paper we used revenues as a measure of the shares' importance. If one uses units of output instead, then the progressive sector's share would always be rising over time.

In this paper we considered the extreme case where in the stagnant sector productivity growth is nil. In spite of the lack of realism of this assumption, as long as there are differences in productivity growth between sectors, then market structure, initial costs and price elasticity will play an important role in determining the evolution of the relative revenues from sectors. Technological progress in the stagnant sector would increase (decrease) the share of that sector if price is on the elastic (inelastic) portion of the demand curve.

The share of the stagnant sector may be increasing, decreasing, or U-shaped in relation to time. This means that one aspect of the cost disease, the rise of expenditures on low productivity growth sectors, is not universally true or false: it depends on market conditions.

\section{References}

[1] Aguirre, Iñaki, Simon Cowan, and John Vickers. 2010. Monopoly Price Discrimination and Demand Curvature. American Economic Review 100, 1601-1615. 
[2] Baumol, William Jack, and William G. Bowen. 1966. Performing Arts-the Economic Dilemma: A Study of Problems Common to Theatre, Opera, Music and Dance. MIT Press.

[3] Baumol, William Jack. 2012. The Cost Disease: Why Computers Get Cheaper and Health Care Doesn’t. Yale University Press.

[4] Cabral, Louis. 1995. Conjectural variations as a reduced form. Economics Letters 49(4), 397402.

[5] Cowen, Tyler. 1996. Why I do not believe in the cost-disease. Journal of Cultural Economics 20(3), 207-214.

[6] Crawford, Allan. 2002. Trends in Productivity Growth in Canada. Bank of Canada Review Spring, 19-32.

[7] Fillic, Rolf Färe, Shawna Grosskopf, Björn Lindgren, and Jean-Pierre Poullier. 1997. Productivity Growth in Health-Care Delivery. Medical Care 35(4), 354-366.

[8] Gabszwicz, Jean Jaskold, and Jacques - Francois Thisse. 1986. On the nature of competition with differentiated products. The Economic Journal 96(381), 160-172

[9] Kalai, Ehud, and William Stanford. 1982. Duopoly, conjectural variations and supergames. Discussion paper \# 525, Northwestern University.

[10] Kask, Christopher, and Edward Sieber. 2002. Productivity growth in 'high-tech' manufacturing industries. Monthly Labor Review 3, 16-31.

[11] O'Mahony, M., and Philip Stevens. 2009. Output and productivity growth in the education sector: comparisons for the US and UK. Journal of Productivity Analysis 31, 177-194.

[12] Perry, Martin. 1982. Oligopoly and Consistent Conjectural Variations. The Bell Journal of Economics 13(1), 197-205.

[13] Trombella, Jerry. 2010. Cost and Price Increases in Higher Education: Evidence of a Cost Disease on Higher Education Costs and Tuition Prices and the Implications for Higher Education Policy. Ph.D. thesis. Seton Hall University Dissertations and Theses. 